\title{
Violência é coisa de homem? \\ A "naturalização" da violência nas falas de homens jovens
}

\author{
Is violence man's thing? \\ The "naturalization" of the violence for young men
}

\author{
Elaine Ferreira do $\mathrm{N}$ ascimento ${ }^{1}$ \\ Romeu Gomes ${ }^{1}$ \\ Lúcia Emília Figueiredo deSouza Rebello ${ }^{1}$
}

Abstract Thestudy aims to analyzetheyoung men's senses attributed to the relation masculinity-violence. The methodology of this study was based on a qualitative approach, trying to understand and situate the underlying senses to the speeches of the investigated subjects, involving 19 young men of popular segments of the city of Rio de Janeiro (RJ). The results revealed that, in general, the relation masculinity-violence-youth might be a vulnerability factor. It is ended that to have another glance on that model, it is necessary the adoption of strategies that facilitate other ways to experience to be man, that invest in a perspective of taking care of itself and other, turning the relationships healthier and with less risks.

Key words Masculinity, Violence, Youth
Resumo 0 estudo tem por objetivo analisar os sentidos atribuídos por homens jovens à relação masculinidade-violência. A metodologia pautou-se numa abordagem qualitativa, em quese procurou compreender e contextualizar os sentidos subjacentes às falas dos sujeitos investigados, envolvendo 19 homens jovens de segmentos populares da cidade do Rio de Janeiro (RJ). Os resultadosapontam que, em geral, a relação masculinidade-violência-juventude pode ser um fator de vulnerabilidade. Conclui-se que, para quesetenha um outro ol har sobreessemodelo, faz-se necessária a adoção de estratégias que possibilitem outras formas de experienciar o ser homem, que invistam numa perspectiva do cuidar de si e dos outros, tornando as relações mais saudáveis e com me nor risco.

Palavras-chave M asculinidade, Violência, Juventude

${ }^{1}$ Departamento deEnsino, Instituto Fernandes

Figueira, Fundação

Oswaldo Cruz. Av. Rui

Barbosa 716, Flamengo.

22250-020 Rio deJaneiro

RJ. elaine@iff.fiocruz.br 
Introdução

Neste estudo, objetivamos analisar os sentidos de homens jovens atribuídos à relação masculinidadeviolência. Entendemos que, por meio dessa análise, poderemos trazer contribuições para as discussões que vêm sendo desenvolvidas no campo da saúde pública em que se problematiza o fato de homens jovensseenvolverem em situações deviolência. Para essa análise, tomamos como referência os conceitos demasculinidade, violênciaejuventude.

A masculinidade - situada nas relações de gênero - pode ser entendida como um conjunto de atributos, valores, funções e condutas que se espera que 0 homem tenha numa determinada cultu$\mathrm{ra}^{1}$. Ampliando a discussão, Connel ${ }^{2}$ considera que os model os de masculinidade e feminilidade além de se relacionarem a outros aspectos estruturais, como raça e classe social - se vinculam a contradições internas e rupturas históricas, fazendo com que haja múltiplas masculinidades, embora podendo haver uma que ocupa um lugar de hegemonia e, por isso, pode se tornar um modelo a ser seguido nas relações de gênero. Esse modelo expressa uma ideologia em que a masculinidade se ancora na heterossexualidade, na racionalidade e no privilégio de poder infligir a violência ${ }^{3}$. Adotando um recorte de geração, consideramos, portanto, que as masculinidades se complexificam ainda mais entreos jovens quando influenciados por esse modelo para ascender ao status de homem adulto.

Em relação à juventude, com baseem Groppo ${ }^{4}$, entendemos essa expressão como uma categoria social - perpassada por questões etárias - configurada, ao mesmo tempo, como uma representação sociocultural euma situação social. N esse sentido, a juventude, tratada como uma concepção, representação ou criação simbólica, se constrói pelos grupos sociais ou pelos próprios sujeitos tidos como jovens, para designar uma série de comportamentos e atitudes a ela atribuídos. Assim, a juventudemetamorfoseia-se deacordo com aclasse social, o grupo étnico/racial, a nacionalidade, o gênero, o contexto histórico nacional e regional, dentre outros aspectos ${ }^{4}$.

No campo da saúde pública, as discussões sobre a masculinidade têm sido atravessadas por questões relacionadas à violência. Segundo Couto e Schraiber ${ }^{5}$, a partir dos anos noventa, principalmente nesse campo, se intensificam as discussões sobre a relação homem-violência, sobretudo motivadas pelos al tos índices de mortalidade por violência entre homens jovens, em diversas regiões da América Latina e Caribe. Schrai ber e colaboradores ${ }^{6}$ chamam a atenção para a magnitude da vio- lência vivida por homens na esfera pública, apontando que cerca de um em cada dois homens já experimentou alguma situação de agressão física. No caso da juventude, esse problema se acirra, por conta da forte participação desse segmento nos atos violentos. Gomes e colaboradores ${ }^{7}$, por exemplo, baseados em dados do Datasus, apontam que, em 2000, mais da metade das mortes por causas externas, entre homens jovens de 15 a 29 anos de idade, ocorreram por homicídio.

Ampliando essa discussão, Souza ${ }^{8}$ observa que o maior envolvimento de homens em homicídiose acidentes de transportes - como vítimas ou como autores - podesearticular com doisgrandes símbolos masculinos: as armas (associadas ao poder de vida ou morte) e os carros (associados ao poder de locomoção, velocidade, liberdade e status social). Esses objetos, segundo a autora, "são introduzidos desde cedo na vida do menino, na forma de brinquedos, e passam a fazer parte do universo masculino com todos os simbolismos que possuem no contexto capitalista ocidental contemporâneo".

As relações entre juventude e violência podem ser aprofundadas se adicionarmos questões voltadas para raça/etnia. No entanto, sabemos que há pouco investimento por parte da área da saúde no trato dessas questões. Junto a uma produção escassa, há autores que chamam a atenção para a necessidade de se contextualizar as relações entre raça/etnia, juventudee violência num escopo maior que envolva, dentre outros, aspectos estruturais - relacionados, principalmente, as desigualdades socioeconômicas, bem como questões de ordem territorial - voltadas para áreas geográficas hoje consideradas de risco ${ }^{9}$.

Por último, observamos que as discussões acerca das relações masculinidade-juventude-violência devem se situar numa lógica complexa em que a violência é entendida como um fenômeno multifacetário e sócio-histórico, nutrida e modelada a partir de aspectos políticos, econômicos e culturais que se traduzem nas relações cotidianas entre os sujeitos e as instituições, sendo este um processo apreendido e internalizado ${ }^{10}$.

\section{Material e método}

Nosso estudo é parte de uma investigação que procurou problematizar a tríade ser homem, juventude eviolência, ancorada no modelo hegemônico de masculinidade. Essa investigação pautou-se numa abordagem de pesquisa qualitativa, aqui entendida como um conjunto de práticas interpretativas que busca investigar os sentidos que os sujeitos atribu- 
em aos fenômenos e ao conjunto de relações em que eles se inserem ${ }^{11}$. Nessa abordagem, procuramos compreender e contextualizar os sentidossubjacentes às falas dos sujeitos investigados.

0 estudo foi desenvolvido com homens jovens, que se encontravam inseridos num curso de qualificação para o mercado de trabalho na área automobilística, promovido por uma Organização Não Governamental (ONG) que atua em uma favela na cidade do Rio de Janeiro. A instituição oferece formação, capacitação e colocação no mercado de trabalho aos jovens de baixa renda. A escolha por esse curso se deu pela facilidade de acesso dos pesquisadores à instituição e por reunir jovens que atendiam aos critérios da pesquisa.

Pautada na lógica deamostra em pesquisa qualitativa ${ }^{12}$, na escolha dos entrevistados foram considerados os sujeitos em números suficientes para que houvesse saturação de sentidos e foi prevista a possibilidade de inclusões sucessivas de sujeitos até que fosse possível uma discussão densa das questões da pesquisa.

Os jovens entrevistados compuseram um grupo de 19 rapazes com idades entre 15 e 17 anos. A maioria tinha 16 anos (15 homens-jovens), autodeclararam-se "pretos" (12 homens-jovens) e cursavam a oitava série do ensino fundamental ( 17 homens-jovens).

A coleta dos dados se apoiou em entrevistas semi-estruturadas. Em termos de procedimento analítico adotado no trato dos depoimentos, neste estudo utilizamos o método de interpretação de sentidos ${ }^{13}$, com baseem princípios hermenêuticosdialéticos para a interpretação do contexto, das razões e das lógicas dos depoimentos que giraram em torno das temáticas do estudo. A partir desse mé todo, procuramos não só compreender os sentidos subjacentes às falas dos jovens, como buscamos interpretar significados culturais mais amplos, por meio da contextualização dos depoimentos. Caminhando nessa trajetória, elaboramosuma síntese interpretativa, procurando articular objetivo do estudo, base teórica adotada e dados empíricos.

0 projeto de pesquisa da qual se insere este trabal ho foi avaliado pelo Comitê deÉtica em Pesquisa com Seres H umanos do Instituto Fernandes Figueira/Fiocruz, em cumprimento da resolução 196/96 do Conselho Nacional de Saúde. Para garantir o caráter sigiloso das informações, os depoimentos dos entrevistados foram codificados com nomesfictícios.
Cenários socioestruturais da masculinidade juvenil

Os depoimentos dos entrevistados refletem aspectos de cenários socioestruturais do cotidiano e das relações entre os sujeitos. Em outras palavras, os textos são construídos a partir de contextos. Assim, nessa perspectiva, para os jovens entrevistados a violência nas comunidades, quase sempre está associada ao tráfico de drogas:

Eu acho muito difícil o jovem de hoje em dia não estar envolvido com a violência dentro das comunidades, até porque eles são encaixados como marginais na sociedade. As polícias se revoltam, mas acabam fazendo as coisas que eles não queriam fazer, masacabam tendo quefazer aquilo (Tiago, 16 anos).

Os policiais poderiam agir de outra forma, mas não, usam de violência nas comunidades. Só porque é comunidade, tudo bem que tem traficante, mas também tem muita gente do bem e, eles não perguntam, saem atirando e quem acaba morrendo [são] os jovens, os envolvidos e os inocentes (Reinaldo, 16 anos).

Eu acho que tudo isso vem da sociedade, a violência é gerada mais pelo homem, por causa que a gente vê aqui dentro [comunidade], muita facção, falando de facção, isso gera muita violência, porque daí eles ficam meio com raiva e quer pegar 0 outro, eu acho que vem em seguida, um vem seguindo 0 outro. É, dando continuidade, eu acho que continua assim, geralmente o homem, a violência só o homem causa (Ricardo, 17 anos).

Essas falas nos remetem a uma discussão mais ampla em que o ser jovem, quase sempre negro, pobre emorador de favela, pode ser alvo de discriminação e marginalização ${ }^{14}$. Wacquant ${ }^{15}$, ao discutir a violência estrutural, a definea partir da combinação de dois processos sociais: a polarização de classes em razão das desigualdades sociais e a segregação racial. Esses dois elementos combinados produziriam o que ele chama de "dualização da metrópole". Essa violência estrutural, por sua vez, poderia causar um processo perverso multifacetado, no qual se destacariam três eixos: desemprego crônico, estigmatização social e racial e exílio. A expressão final dessa violência teria como resultante a vulnerabilidade de um segmento que já se encontra, por questões etárias, num grau elevado de fragilidade.

A concepção de vulnerabilidade diz respeito à análise não apenas dos sujeitos, mas também do contexto ao qual estão inseridos, considerando as estruturas sociais vulnerabilizantes ou condicionamentos de vulnerabilidades ${ }^{16-18}$. A dialética possível em tal conceito refere-se tanto aos fatores ne- 
gativos, ou seja, aos obstáculos para os sujeitos e aos riscos vivenciados pelos mesmos, quanto aos fatores que podem ser entendidos como positivos, na medida em que os sujeitos criam formas de resistências e estratégias para o enfrentamento dos riscos e obstáculos de forma criativa.

Ampliando a discussão sobre violência estrutural, Minayo e Souza ${ }^{19}$ observam que essa tem atingido diretamente a juventude brasileira, de modo que o principal grupo de risco para a mortalidade por homicídio tem sido homens jovens e adultos, moradores de bairros pobres de metrópoles, negros, com baixa escolaridade e qualificação profissional.

Nesse sentido, a chamada forma estrutural da violência, muitas vezes oculta numa fachada de inevitabilidade histórica da pobreza, da desigualdade, da ineficácia da garantia de direitos, pode tornar invisíveis os mecanismos que geram interesses ou privilégios na construção e perpetuação de tais quadros de exclusão e segregação.

\section{Sociabilidade masculina e violência}

$\mathrm{Na}$ construção das identidades de gênero, a sociabilidade - ancorada em modelos culturais - exerce papel estruturante, uma vez que o ser homem ou o ser mulher não se constitui apenas a partir de model os de masculinidade ou feminilidade, mas também são mediados pelas relações intersubjetivas, de modo a reproduzir ou a reconstruir tais modelos de acordo com as situações e as especificidades sociais. Assim, nesse processo de construção/reprodução das identidades, esses modelos funcionam como matrizes - social e historicamente construídas - e se traduzem em habitus, entendido como conhecimento adquirido e determinado pela posição social do indivíduo, estruturando práticas erepresentações que podem ser objetivamente "regulamentadas" e "reguladas", envolvendo uma capacidade criadora, ativa e inventiva ${ }^{20}$. Esses habitus não só são incorporados pelos sujeitos como também adaptados e partilhados nos grupos de pares.

Seguindo essa lógica, de acordo com os depoimentos dos jovens, a violência vista como um ethos masculino, pode ser expressa e apreendida nas re lações sociais entre homens do mesmo grupo etário ou entre gerações diferentes:

É por quetem as brigas, por exemplo, nos campos de futebol, nos botecos, coisas assim, eaí vocêvai ver é o homem que tá lá sendo violento (Ricardo, 17 anos).

Elevê que um homem adulto tá fazendo e acaba se baseando naquilo. Porqueo adulto de al guma for- ma é referência pro jovem. Q uase sempre o jovem é reflexo do homem adulto (Romário, 16 anos).

A partir desses sentidos, a violência teria como lócus privilegiado de ações natural mente violentas o espaço da sociabilidademasculina. Welzer-Lang ${ }^{21}$ observa que, nos lugares monossexuados, como pátios de colégios, clubes esportivos, bares, prisões, entre outros, para ser aceito como homem ou para fazer parte de um grupo de homens, meninos vivenciam uma aprendizagem mimética, na qual o mimetismo dos homens é um mimetismo de violências, que inicialmente se voltam contra a si mesmo e depois se voltam para os outros, sejam mulheres ou homens que não conseguiram atingir esse status.

Esse argumento é reforçado por Bourdieu ${ }^{22}$, ao discutir que a perseguição ideal do modelo de masculinidade podeser o princípio de uma grande vulnerabilidade para os homens, uma vez que pode estimulá-los à adoção de investimento em jogos violentos masculinos.

A masculinidade, como prática pessoal, não pode ser isolada deseu contexto socioinstitucional (família/estado/mercado/trabalho/grupo de pares). Ou seja, a masculinidade tem um status de instituição produzida na vida diária a partir de relações interpessoais, inter-relacionais e entre os sujeitos.

Essa luta, entretanto, tem um ritmo evariáveis próprias e não está conscientemente vinculada a um grupo de homens, mas a uma trama de relações complexas, em que se procura ajustar, legitimar e velar as características históricas e culturais da masculinidade, tornando-a estabelecida, eterna, natural e, portanto, ahistórica. E, em particular, os joven s entrevistados fazem parte de um segmento socioeconomicamente fragilizado e estão inseridos na instituição em busca de melhores oportunidades de renda e vida, o que pode demarcar diferenciadamente 0 ol har destes jovens.

\section{Ser homem é ser violento (?)}

A incorporação da divisão social do sexo, instituída a partir dos modelos culturais de gênero, pode fazer com que determinadas estruturas da ordem social sejam naturalizadas. Dentro dessa lógica por meio do processo de "naturalização" - certas características que compõem o modelo hegemônico podem ser vistas como uma manifestação biologicamente estabelecida ${ }^{23}$. Assim, a estrutura de dominação, que comumenteé associada à masculinidade, no âmbito das relações de gênero pode contribuir para quea violência seja associada cons- 
ciente ou inconscientemente ao ser homem. N esse sentido, para alguns entrevistados, a violência é algo que tende a ser internalizada e naturalizada pelos homens. $E$, nas relações de gênero, a violência só se relaciona com o feminino quando é uma resposta à violência masculina ou quando é uma causa para essa.

O homem naturalmente ele já é violento (Roberto, 16 anos).

Eu acho que ser homem é ser violento, até porque o homem é mais violento que mulher (Rafael, 16 anos).

Algumas pessoas acham que pra ser homem tem que ser violento. Ah! H omem équando dá porrada, quando faz isso, quando faz aquilo e eu acho que não, eu já acho diferente (Rico, 16 anos).

O s homens arrumam mais violência na maioria das vezes por causa demulher. Por queeles saem com a mulher, aí outro cara ol ha pra mulher dele e aí acaba gerando uma briga (Rafael, 16 anos).

Seela [a mulher] causa [violência] éem resposta ao homem, ela dá o troco, mas geralmente quem começou foi o homem (Ricardo, 17 anos).

De acordo com Bourdieu ${ }^{20}$, as relações entre os gêneros são constituídas a partir de uma ordem social em que simbolicamente a dominação masculina pode ser ratificada como um habitus masculino. A legitimação do domínio do masculino sobre o feminino dentro da ideologia de supremacia pode ocorrer por meio do uso da violência, outorgando aos homens, que partilham da visão hegemônica de que a dominação é uma pertença da masculinidade, 0 direito de usá-l $a^{24}$.

Ampliando essa discussão, Connel ${ }^{24}$ problematiza o fenômeno da violência como uma construção social, historicamente associada à masculinidade. Particularmente entresegmentos juvenis, em determinados contextos, a violência pode ser um instrumento de uso recorrente para a afirmação da masculinidade de homens jovens sobre outros homens da mesma faixa etária, seja entre grupos de pares, seja entre grupos diferentes.

Se o ser homem é mais vulnerável à violência, 0 ser homem jovem pode acirrar essa vulnerabilidade. Na medida em que a juventude pode ser entendida como um statusintermediário entrea infância e a fase adulta, o jovem, para acessar o status de ser homem, podese deparar com a violência como um caminho a ser trilhado. N esse sentido, se o ser masculino é associado ao ser violento, a construção da identidademasculina passa também pelo lidar com a violência, seja como autor ou como vítima, papéis que ora se excluem, ora se superpõem. Assim, nossos entrevistados trazem em suas falas questões que podem remeter a essa discussão:
0 jovem, elenão sabedireito o quequer e[como] alcançar os objetivos deles, então muitas vezes ele encara a violência como a melhor forma de subir na vida e em alguma coisa (Roberto, 16 anos).

Quando eu sou jovem, eu começo a me dedicar à violência (Renato, 17 anos).

Percebida como um caminho, a violência pode ser vista, ao mesmo tempo, por alguns dos nossos jovens como um instrumento de superação deuma dada situação em que elese encontra, um mecanismo para realização de seus objetivos, um modelo a ser seguido ealgo inevitável a ser experimentado.

Ainda que o homem reflita sobre a não pertinência do exercício da violência como afirmação da masculinidade no âmbito das relações nem por isso deixa de ter uma performance violenta. Isso fica patente no depoimento de um dos nossos entrevistados:

Você com raiva, você gera violência, mais depois você pára pra pensar e pensa, pô não era pra eu ter feito isso. Coisa de homem e babaca. Acho que todo homem tem esse momento babaca defazer as coisase depois se arrepender (Ricardo, 17 anos).

Esse depoimento, de uma forma ou de outra, reedita um model o hegemônico de masculinidade que assegura a posição dominante de homens e a subordinação de mulheres. Entretanto, como bem observa Connel2, ${ }^{24}$, esse modelo não é totalmente dominante, na medida em que convive com outras formas de masculinidade, ainda que se sobressaia sobre essas. Ilustrando esse posicionamento, a fala que segue pode nos fazer refletir sobre a convivência dos diversos modelos de masculinidade existente no cotidiano, gerando um possível questionamento de que a violência não é um fenômeno tão naturalizado:

Bem, é que tem algumas pessoas que acham que pra ser homem tem que ser violento. Ah! Homem é quando dá porrada, quando faz isso, quando faz aquilo e eu acho que não, eu já acho diferente (Rico, 16 anos).

A discussão acerca da relativização da violência, como pertença do ser homem, podeser ampliada a partir da própria concepção da masculinidade hegemônica de Connel que, segundo Adibi ${ }^{25}$, se opõe a uma visão essencialista de gênero e se recusa a transformá-la numa identidade fixa e estática de um gênero. N esse sentido, a masculinidade hegemônica refleteuma dinâmica em queo que é hegemônico e o que é subordinado sejam vistos mutuamente como contraponto eantiparadigma ${ }^{26}$. Assim, a construção da masculinidade cria erecria, transforma e ressignifica, provocando rupturas ou permitindo a continuidadeea legitimação das idéias predominantes. Esse processo contém a luta con- 
tínua que envolve marginalização, contestação, mobilização, resistência e subordinação.

\section{Consideraçõesfinais}

Tanto os dados deste estudo quanto os da literatura nos apontam que as relações estabelecidas entre masculinidade ejuventude podem redundar em práticas violentas, trazendo comprometimentos para a saúde dos homens jovens, na medida em que esses sujeitos, ao almejarem o status de ser homem, podem ser influenciados pelo modelo he gemônico de masculinidade, associado à dominação e ao ser forte. N esse sentido, os jovens, para se afirmarem ou serem aceitos como homens de"verdade", de um lado, passam a dominar todos aque les que julgam mais "fracos" - sejam mulheres, sejam outros homens - e, de outro, caindo na sua própria armadilha, se expõem a riscos, comprometendo a saúde ou a vida de si ou dos outros.
A partir dessa perspectiva, as consequências das relações masculinidade-violência-juventude paraa saúde pública se expressam fortemente nos perfis de mortalidade por causas externas, trazendo não só custos para o Estado como também desafios a serem enfrentados frente a um problema tão complexo e multifacetado.

Caminhando na direção do enfrentamento de tal problema, alguns princípios podem ser esboçados; o primeiro deles se relaciona à necessidade de envolver os homens jovens como protagonistas da construção de um olhar a partir de outros horizontes; o segundo se traduz pela reconstrução de novos sentidos para que os jovens possam trilhar novos caminhos que desnaturalizem a violência como pertença do masculino, construindo a possibilidade de ser homem numa perspectiva do cuidar de si e dos outros, tornando a vida e as relações mais saudáveis e com menos riscos.

\section{Colaboradores}

EF N ascimento participou da concepção, delineamento e redação do artigo, análise e interpretação de dados, R Gomes participou do delineamento, redação do artigo, análise e interpretação de dados, LEFS Rebello participou da redação e revisão crítica do artigo. 


\section{Referências}

1. Keijzer B. Hasta donde el cuerpo aguante: género, cuerpo y salud masculina. In: Caceres C, Cueto $M$, Ramos M, coordinadores. La salud como derecho ciudadano: perspectivas y propuestas desde América Latina. Lima: Facultad de Salud Pública y Administración de la Universidad Peruana Cayetano Herida; 2003. p. 137-152.

2. Connel RW. On hegemonic masculinity and violence: response to Jefferson and $\mathrm{H}$ all. Theoretical Criminology 2002; 6(1):89-99.

3. Villaseñor-Farias M, Castañeda-Torres J. M asculinidad, sexualidad, poder y violencia: análisis de significados en adolescentes. Salud Pública de M éxico 2003; 45(1):544-557.

4. Groppo LA. Juventude: ensaios sobre sociologia e história das juventudes modernas. Rio de Janeiro: Difel; 2000.

5. Couto $M T$, Schraiber LB. Homens, saúde e violência: novas questões de gênero no campo da saúde coletiva. In: Minayo MCS, Coimbra Jr. CEA, organizadores. Críticas e atuantes: ciências sociais e humanas em saúde na América Latina. Rio de Janeiro: Fiocruz; 2005. p. 87-706.

6. Schraiber LB, Gomes R, Couto MT. Homens na pauta da saúde coletiva. Cien Saude Colet 2005; 10(1):7-17.

7. Gomes R, M inayo M CS, Silva CFR. Violência contra a mulher: uma questão transnacional e transcultural das relações de gênero. In: Brasil. Impacto da Violência na Saúde dos Brasileiros. Brasília: Secretaria de Vigilância em Saúde, Ministério da Saúde; 2005. p. 117-140.

8. Souza ER. Masculinidade e violência no Brasil: contribuições para a reflexão no campo da saúde. Cien Saude Colet 2005; 10(1):59-70.

9. Cechetto $F, M$ onteiro S. Discriminação, cor e intervenção social entre jovens na cidade do Rio de Janeiro (RJ-Brasil) : a perspectiva masculina. Estudos feministas 2006; 14(1):199- 218.

10. M inayo MCS. Violência social sob a perspectiva da saúde pública. Cad. Saude Publica 1994; 10 (Supl 1): 7-18.

11. Deslandes SF, Gomes R. A pesquisa qualitativa em serviços de saúde: notas teóricas. In: Bosi MLM, Mercado FJ, organizadores. Pesquisa qualitativa de serviços de saúde. Petrópolis: Vozes; 2004. p. 99-120.

12. M inayo MCS. 0 desafio do conhecimento: pesquisa qualitativa em saúde. São Paulo: Hucitec; 2006.

13. Gomes R, Souza ER, M inayo MC, Silva CFR. Organização, processamento, análise e interpretação de dados: o desafio da triangulação. In: M inayo MCS, Assis SG, Souza ER, organizadores. Avaliação por triangulação de métodos: abordagem de programas sociais. Rio de Janeiro: Fiocruz; 2005. p.185-221.
14. Wacquant L. Punir os pobres: a nova gestão da miséria nos Estados U nidos. Rio de Janeiro: Freitas Bastos Ed; 2002.

15. Wacquant L. Os três corpos do lutador profissional. In: Lins D, organizador. A dominação masculina revisitada. Campinas: Papirus; 1998. p.73-96.

16. Vignoli JR. Vulnerabilidad demográfica en América Latina: qué hay de nuevo? In: Seminario Vulnerabilidad. Santiago: Cepal; 2001.

17. Filgueira $\mathrm{CH}$. Estructura de oportunidades y vulnerabilidad Social: aproximaciones conceptuales recientes. In: Seminario Vulnerabilidad. Santiago: Cepal; 2001.

18. Arriagada I. Familias Vulnerables 0 Vulnerabilidad De Las Familias? In: Seminario Vulnerabilidad. Santiago: Cepal; 2001.

19. M inayo MCS, Souza ER. É possível prevenir a violência? Reflexões a partir do campo da Saúde Pública. Cien Saude Colet 1999; 1(4):7-32.

20. Bourdieu P. Esboço de uma teoria da prática: precedido de três estudos de etnologia Cabília. Portugal: Celta; 2002.

21. Welzer-Lang D. A construção do masculino: dominação das mulheres e homofobia. Rev Est Feministas 2001; 2:460-482.

22. Bourdieu P. A dominação masculina. Rio de Janeiro: Bertrand Brasil; 1999.

23. Gomes R. Sexualidade masculina, gênero e saúde. Rio de Janeiro: Fiocruz; 2008 .

24. Connell RW. Understanding men: Gender sociology and the new international research on masculinities. [acessado 2007 set 22]. Disponível em: www. europrofem.org/contri/2_04_en/research-onmasculinities.pdf

25. Adibi $\mathrm{H}$. Sociology of masculinity in the Middle East. Paper presented to the social change in the 21 Century Conference. [acessado 2007 set 23]. Disponível em: www.socialchange.quat.edu.au/conferences/ socialchange/docs/conf_papers2006/adibi_fin.pdf

26. Cecchetto FR. Violência e estilos de masculinidade. Rio de Janeiro: Fundação Getúlio Vargas; 2004.

Artigo apresentado em 21/08/2008

Aprovado em 19/01/2009 